\title{
FEATURE Innovation platforms for sustainable land management in East African landscapes: Stewardship, incentives, and challenges
}

\author{
Tilahun Amede and Pascal Sanginga
}

$\mathrm{T}$

his paper examines the potential role of innovation platforms (IPs) in facilitating the adoption and scaling up of Sustainable Land Management (SLM) practices in East Africa, where land degradation has been a prime challenge affecting food security, livelihoods, and environmental services. Land degradation in Ethiopia has been costing about $3 \%$ of the agricultural gross domestic product with an estimated value of US $\$ 7$ billion over a 20 -year period (Berry 2003). Similarly, communities around Mount Elgon in Uganda have been seriously affected by land degradation in multiple ways, including recurrent landslides, which have caused many deaths and destroyed livelihoods (Edwards 2012).

Two traditional ways to deal with natural resource issues are either to organize individual farmers to better manage resources or to impose a solution from outside, commonly by government institutions. Both are found to be unsatisfactory: the first fails to bring in outside resources to deal with community needs, while the latter fails to consult adequately with members of local communities. Innovation platforms are avenues to enhance such interaction among different parties (Nederlof et al. 2011; Hall et al. 2001). An IP is a holistic approach, which involves a diverse set of actors and exploits linkages for improved action, coordination, and behavioral changes. Innovation platforms could be used to facilitate organization and action of multi-institutional, multidisciplinary actors and enable them respond to changing, complex institutional and environmental challenges (Hall et al. 2001), exchanging knowledge and generating innovation. Van Rooyen and Homann (2011) claimed IPs generated site-specific solutions to align production with market requirements and ensured better prices for smallholder producers. Similarly, the

Tilahun Amede is principal scientist at the International Crops Research Institute for Semiarid Tropics, Nairobi, Kenya. Pascal Sanginga is senior program specialist, International Development Research Centre, Nairobi, Kenya.
East Africa Dairy Development program used IPs to facilitate partnerships, enabling competitiveness and improving livelihoods of smallholder dairy systems (Kilelu et al. 2012). However, the roles of individuals and organizations in IPs may also change, not only as a result of a change in platforms' objectives or strategies, but also as a result of internal reflection and learning (Nederlof et al 2011). These positive developments encourage various research and development actors to test potential contributions of IPs for scaling up local successes and improving market opportunity (Van Rooyen and Homann 2011) collective action (German et al. 2012), and policy influence. However, there has been limited evidence on whether they could be used for solving more complex issues such as SLM. Using case studies from Ethiopia and Uganda, this paper presents findings on the effectiveness of IPs for scaling up and managing natural resources by local actors, and the incentives required to enable active and successful engagement of IPs at local and higher levels.

\section{METHODOLOGY}

Innovation platforms were initiated as part of a four-year project (2008 to 2012) on SLM, financed by International Development Research Centre in Canada (IDRC) and implemented by African Highlands Initiative, Ethiopian Institute of Agricultural Research (EIAR), and Ugandan National Agricultural Research Organization (NARO), to facilitate the devolution and scaling up of SLM interventions developed by national and international research centers to resources-poor, small-scale farmers. It was implemented in Kapcherwa and Bukwa districts of Uganda, and Dendi and WereJarso districts of the central Ethiopian Highlands (table 1). The planning and implementation of the IP project was assessed using four methods: review of relevant documents, focus group discussions, key informant interviews, and field observation. A generic checklist was iteratively developed to extract relevant information (Amede et al. 2004). Available literature was assembled and studied prior to three weeks of field visits, from April 3 to April 26, 2012.

In both countries, we conducted series of meetings with core research teams; one on one discussions with project leaders, research directors, and site coordinators; and a roundtable discussion with district officials and nongovernmental organizations (NGOs). We had site visits to the watersheds and group discussions with communities, watershed IP leaders, and the wider IP members. We also interviewed donors about expectations, achievements, and impressions.

The data obtained from the interviews were fine-tuned through key informants. Review of secondary data helped to gain a general understanding of the project background, its rationale, approaches, methods, outputs, outcomes, and lessons learned. The cases were analyzed using an assessment framework developed to evaluate partner views of project achievements. The tool enables comparisons between the actual outcomes of a research project with the expected outputs had the research process been successful, making a visible contribution (Amede et al 2004). The final output from the assessment was presented to a wider forum for feedback and validation in the presence of country teams from Ethiopia and Uganda, donors, and policy makers on May 24, 2012, in Addis Ababa, Ethiopia.

Case Study 1: Local Innovation Platforms in Kapcherwa and Bukwo Districts of Uganda. The Mount Elgon region of Uganda has been a hotspot of landslides and flooding in the last decade, aggravated by recent settling and farming practices. It took the lives of hundreds and created a continuous threat to livelihoods of both upstream and downstream communities. In 2012, Minister of Disaster Preparedness and Refugees Stephen Mallinga stated, "It is feared the landslide and floods buried about 29 homes with about 30 people dead. Up to 400,000 people could require humanitarian aid as the rain intensified, forcing them to abandon their homes for fear of further mudslides" 


\section{Table 1}

Biophysical and socioeconomic characteristics of study sites.

\begin{tabular}{lllll}
\hline Characteristics & Dendi, Ethiopia & Werejarso, Ethiopia & Kapcherwa, Uganda & Bukwo, Uganda \\
\hline Coordinates & $9^{\circ} 1^{\prime} 41^{\prime \prime} \mathrm{N}, 40^{\circ} 4^{\prime} 89^{\prime \prime} \mathrm{E}$ & $9^{\circ} 48^{\prime \prime} \mathrm{N}, 38^{\circ} 44^{\prime \prime} \mathrm{E}$ & $1^{\circ} 13^{\prime} 3^{\prime \prime} \mathrm{N}, 34^{\circ} 55^{\prime \prime} \mathrm{E}$ & $1^{\circ} 16^{\prime \prime} \mathrm{N}, 34^{\circ} 44^{\prime \prime} \mathrm{E}$ \\
Altitude $(\mathrm{m})$ & 2,300 & 2,200 & 1,800 & 2,000 \\
Mean rainfall $(\mathrm{mm})$ & 1,300 & 950 & 1,270 & 1,300 \\
Landscape position & Undulating, hillsides & Undulating, mostly flat & Hillsides & Hillsides \\
Land tenure & Public & Public & Private & Private \\
Research support & High & Low & Medium & Low \\
Extension service & Public, strong & Public, medium & Decentralized, mainly NGOs \\
Major enterprises & Teff, wheat, legumes, livestock & Teff, wheat, legumes, livestock & Maize, beans, coffee, banana & Maize, beans, coffee, banana
\end{tabular}

(Edwards 2012). Located in the upper part of the watershed, these districts are considered the major sources of erosion and runoff due to recent deforestation for farming (since 1984), with limited conservation structures and poorly managed cereal-based farming systems (figure 1). A transfer of power, functions, and responsibilities for planning and implementation of agricultural extension services from the Ministry of Agriculture, Animal Industry, and Fisheries to district local governments have decentralized the extension system in Uganda. Extension workers at the district level were put under direction of local district governments (Friis-Hansen and Kisauzi 2004). However, except for areas serviced by NGOs, the majority of the country does not readily access extension services because districts are unable to cover operational expenses (IFPRI 2012). Due to the extent of land degradation, farmers in Kaseko Watershed, Kapcherwa, organized self-help watershed groups as early as 2004 and became local champions in managing their landscapes. The project has facilitated the formation of two levels of IPs: community innovation clusters and district-level IPs. At the community level, an elected steering group consisting of a chairman, vice chairman, secretary, treasurer, and members representing various end user groups from different villages were responsible for making locallevel operational decisions but also liaising with district IP leadership. The district IP was formed in close interaction with district administration and included NARO, Benet IP (a self-organized farmers' group), a district National Agricultural Advisory Services coordinator (extension), the Kapcherwa farmers association, and community leaders. NGOs rarely participated.
The community innovation clusters were responsible for creating collective action and implementing SLM interventions at their respective watersheds, while district-level IPs were established to link community action with local government and policy influence. Community innovation clusters became well organized, developed skills in dealing with officials and researchers, and were keen to bring about change in their landscapes. The IDRC project capitalized on these groups to strengthen their organizational capacity, leverage policy support, and facilitate wider landscape influence.

The involvement of farmers in planning, implementation, and evaluation of SLM interventions was substantially improved despite limited access to improved technologies and practices. The fora gave farmers the opportunity to contribute and, in many cases, foster more innovation, even without researcher inputs. Farmer abilities to experiment independently increased, including bearing associated risks and costs.

Innovation platform members in Kaseko Watershed, Kapcherwa, often considered themselves "models" responsible for generating knowledge on behalf of the wider community; this has encouraged them to continue testing and experimenting on their own (figure 2). They have even coined a slogan for collective action, displaying their collective spirit and desire to improve their degraded landscapes. Pioneer local groups known as "uniform wearers" emerged from within the IPs. The local "uniform" that differentiates them from other community members is the construction of terraces and waterways and planting of trees in their farms and home gardens (figure 3). For nonmembers to be part of the group they first need to show a well-established "uniform." Moreover, they demanded interventions and policy support from their local and district councils. The community bylaws, which were jointly developed by researchers and local officials (ASARECA 2012), in consultation with community representatives, addressed some of the policy gaps and were instrumental to mobilize the community or curb livestock roaming. Those who were not responsible were fined both in monetary terms and social sanctions. The Badwoo district has already established seven additional community innovation clusters capitalizing on two IPs supported by the project. Due to these achievements they have received additional grants of 20 million Ugandan shilling (about US $\$ 10,000$ ) from President Museveni, following his visits to the district to capitalize on the "positive initiatives." However, although the project has been successful in creating local institutional capacity at community scales, it was not successful in scaling up LM technologies and practices beyond IP members.

Researchers claimed their attitude toward farmers changed due to their close interaction with local IPs. Working with farmers improved their knowledge of farmers' circumstances, needs, and priorities. The positive effect was observed in Buginyanya Zonal Agricultural Research and Development Institute of NARO, Eastern Uganda, where researchers slowly shifted from commodity-dominated thinking toward integrated approaches.

Case Study 2: Local Innovation Platforms in Dendi and Warajarso Districts of Ethiopia. The same project, in partnership with Holleta Research Centre of EIAR, used IPs to scale up SLM interventions and devolve responsibilities in two districts in 


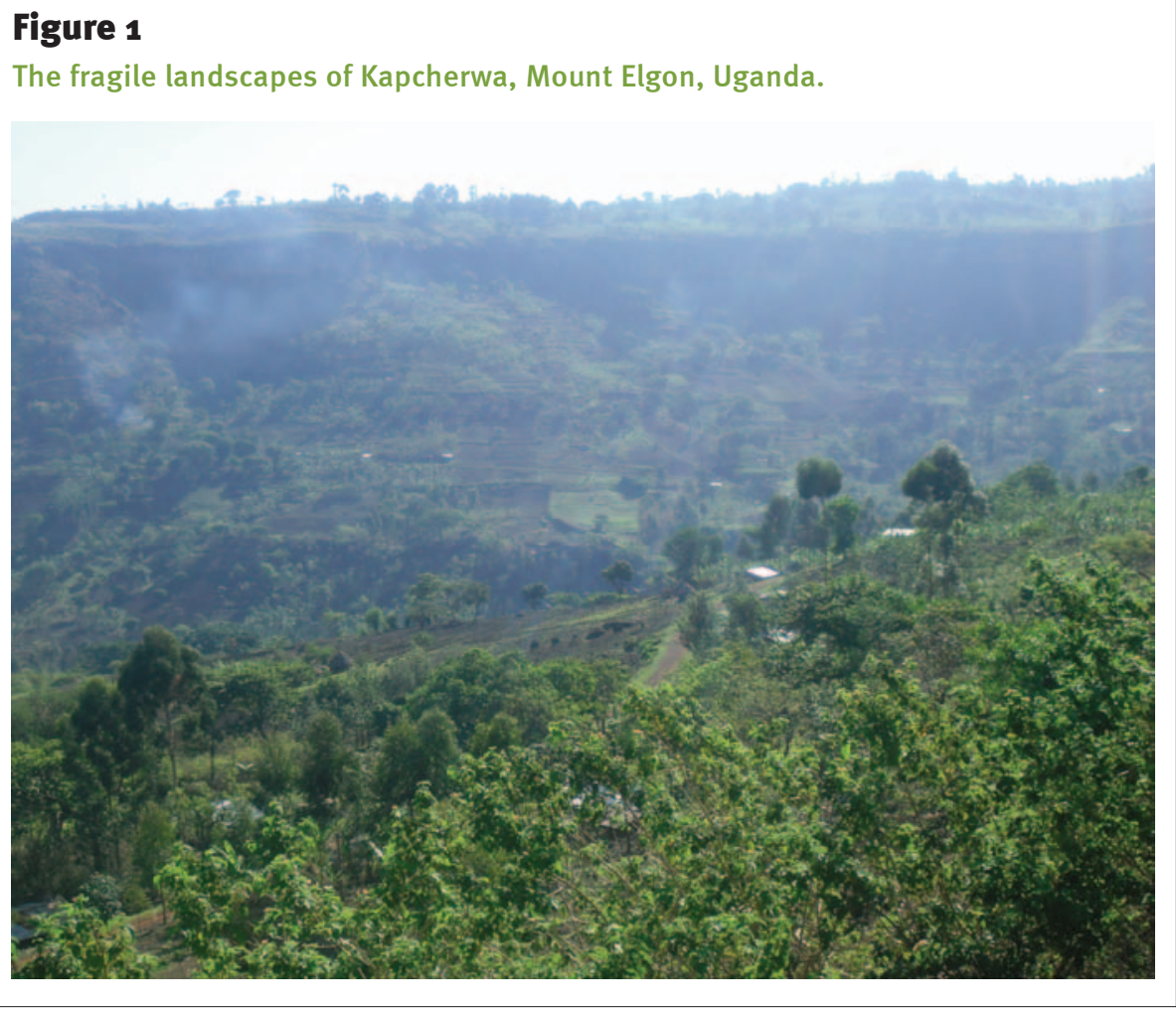

\section{Figure 2}

Innovation platform members in Kapcherwa, Uganda.

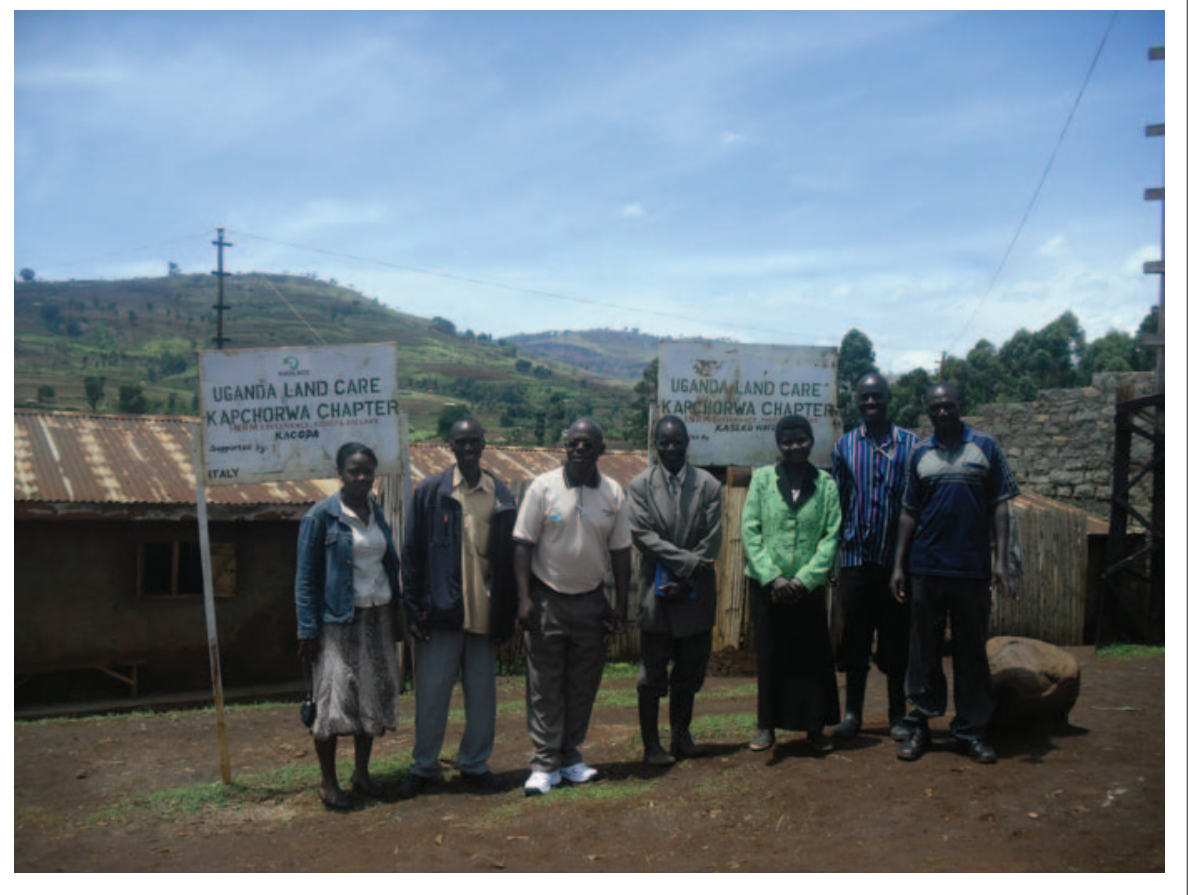

Ethiopia. The district extension department of the Bureau of Agriculture is responsible for disseminating technologies and agricultural practices to farmers through development agents (DAs), assigned at the structures similar to those in Uganda. At the district level, the IP in Dendi was composed of the EIAR, Canadian Physicians for Aid and Relief (CPAR; NGO), Water Action (NGO), Save the Children (NGO), German Society for International Cooperation, local government office heads, DAs, and community leaders. In WereJarso, IP members were EIAR, CPAR, Water Action, Hunde (local NGO), Oromia Saving and Credit Association, local government representatives, DAs, and community leaders. The steering groups selected from different villages were responsible for making local-level operational decisions but also liaising with district IPs. The district IP was formed in close interaction with district administration, and almost all district offices participated during IP establishment.

In both Ethiopian sites, the project was operating in degraded, vertisol-dominated areas practicing crop-livestock systems and predominantly growing teff (Eragrostis tef; a unique cereal preferred to make a local bread called Enjera) along with diverse cereals and legumes (figure 4). The farmers claimed that the project has responded to their priorities by introducing soil and water management interventions, improved crop and fodder varieties, and improved livestock breeds. It also organized farmers for collective action and assisted farmers in developing and adopting bylaws. Besides constructing about $187 \mathrm{~km}$ (116 mi) long soil bunds, the project introduced improved crossbreed cows in Dendi and Werejarso, following the Heifer International model, which positively changed the attitude of farmers. For instance, an elderly farmer in WaraJarso replaced his low-production herd with an improved breed, enabling earnings of about net US $\$ 250$ per month from milk sales to cooperatives. Planting fodder trees and perennial grasses on terraces and gullies to feed his dairy cows then became an incentive.

Another farmer referred the IP project as a means of "activating change within the community." Communities understood their natural resources better and realized the need to manage them more effectively. Moreover, this engagement attracted attention of regional governments, and lead offices received awards and certificates from the government for their "outstanding 


\section{Figure 3}

The perceived landscape changes in Kaseko Watershed, Kapcherwa.

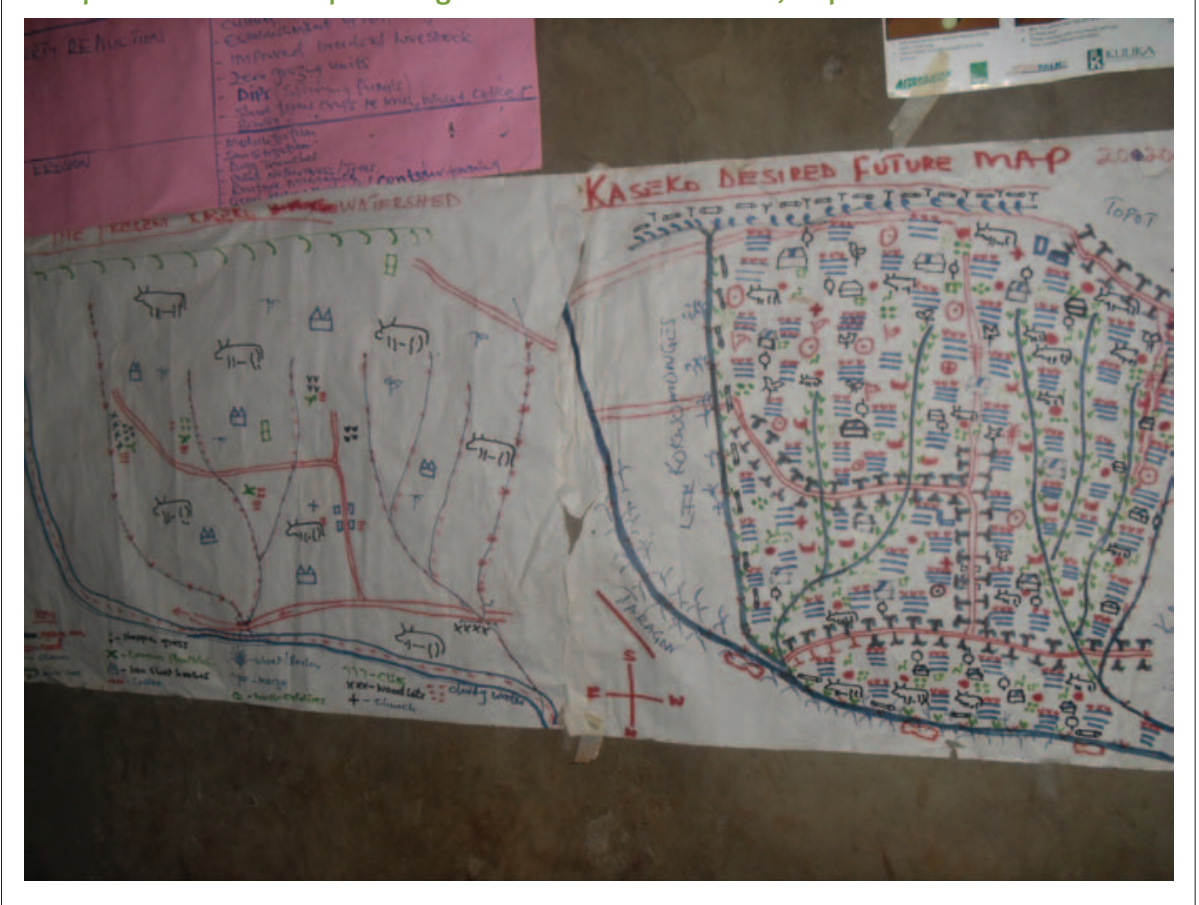

contribution to agricultural development." This process has also encouraged district officers to visit their watersheds more often than usual. The bylaws were used by the IPs as enforcement mechanisms. For instance in Dendi, the first incident of a cow grazing a protected area will cost a farmer a strong warning, while the second incident would cost US\$0.50 and the third, US\$5.The local jury refers the incident to a district council for further incidents. However, bylaws could be sometimes nonfunctional in cases involving powerful community members (e.g., chair persons, wealthy individuals, and politically affiliated persons).

Local government officials may have benefited from linkages created between them and IP members (researchers, NGOs, teachers, and traders). There was also a growing confidence among these actors in jointly addressing productivity and resource management issues. For instance, the Office of Agriculture in WereJarso recognized and appreciated the role of traders for the first time in availing inputs and linking farmers to the market; they have been otherwise labeled as middlemen taking most of the profit margins from farmers. EIAR has institutionalized IPs as a scaling up platform to disseminate their SLM interventions to wider com- istration since the site was considered a showcase for their political ambitions.

3. Farmers were easily accessible to DAs given the associated benefit in terms of access to inputs and technologies.

The timing of the initiative was also right as local governments have set land and water management as a development priority within their own budgets. Their involvement attracted the NGO sector, which are not commonly keen to work with researchers. They claim the approach has influenced the ongoing national campaign for SLM in central Ethiopian Highlands. Innovation platforms have also benefited from the campaign by use as demonstration sites.

It is unclear whether researchers would make an effort to continue facilitate IPs once donor support has dried up. Although these IPs were facilitated by research organizations who themselves have a stake in the process, there is a need to capacitate other actors in the platform to take over some of the critical innovation brokering tasks after project funding comes to an end to sustain innovation processes (Swaans et al. 2013). Going to scale with SLM interventions is also of less interest to politicians; a local council member of Kapcherwa in Uganda said, "Land management does not attract votes while distributing seeds and fertilizers do." Innovation platforms created fora for farmers and government officials for direct interaction; farmers expressed problems and voiced demands to higher officials. It also helped local officials to evaluate and reward extension staff through direct feedback.

\section{INFLUENCE OF INNOVATION PLATFORMS ON INSTITUTIONS AND PROCESSES}

Those who most benefited from the IPs were DAs:

1. They received easy access to a variety of technologies and practices from research centers, particularly in Dendi and WereJarso sites. The availability of extra funds for frequent travel outside their duty stations was also seen as an incentive.

2. The DAs received much stronger political support from the district admin-

\section{SUCCESS FACTORS IN OPERATIONALIZATION OF INNOVATION PLATFORMS}

Inclusive Partnership and Facilitation. Innovation platforms require involvement of different stakeholders at various stages of the innovation processes (Hall et al. 2001). The relationship among partner institutions was variable, ranging from partnership at equal footing to more top-down types of relationships. The strength of partnership also varied depending on historical linkages and interactions, priority domains of institutions, presence and engagement of NGOs, facilitation skills of lead institu- 
tions, and availability of funds for nurturing functional partnerships. There were two different types of partners: those on the ground working directly with communities at watershed scales and those external actors having influence on actions on the ground. Both groups played an important role in facilitating IPs. While membership in district platforms was based on institutional representation, the watershedlevel partnership was demand-driven and strong. Partnership was more difficult in the Ugandan sites, where the involvement of local government was casual, which affected the commitment of most NGOs since they follow the interest and guidance of government officers. A particular challenge was to link grassroots planning at the watershed level (watershed IPs) with district IPs and higher-level decision-making processes. The diversity and quality of partnership would also influence policy interaction and feedback. However, partnership at both scales was hampered by lack of incentive mechanisms (e.g., joint benefits) and poor facilitation capacity. Involvement of key actors was minimal and mostly represented by low-level officers, who did not have power to make critical decisions. In general, the challenge of regularly providing sitting allowances (informal payments for attendance of high-level participants) has been killing IP initiatives in the region. Moreover, the involvement of nonagricultural actors (e.g., traders, processors, and decision makers) was minimal or totally absent because measures were not commonly economically rewarding.

Facilitation. The operationalization of IPs was also affected by weak facilitation and coordination capacity of research institutions. The task of a facilitator in the context of IPs goes beyond merely facilitating meetings and managing dynamics between a bounded groups of actors (Swaans et al. 2013). Rather, "innovation brokering" is required, which involves stimulating interactions with a wide range of actors, often operating at different levels with diverse interests (Swaans et al. 2013). Researchers and DAs had limited experience and capacity in brokering partnerships and responding to emerging partnership challenges. They were not backed by appropriate skills in com-

\section{Figure 4}

Crop livestock systems in the Ethiopian Highlands.

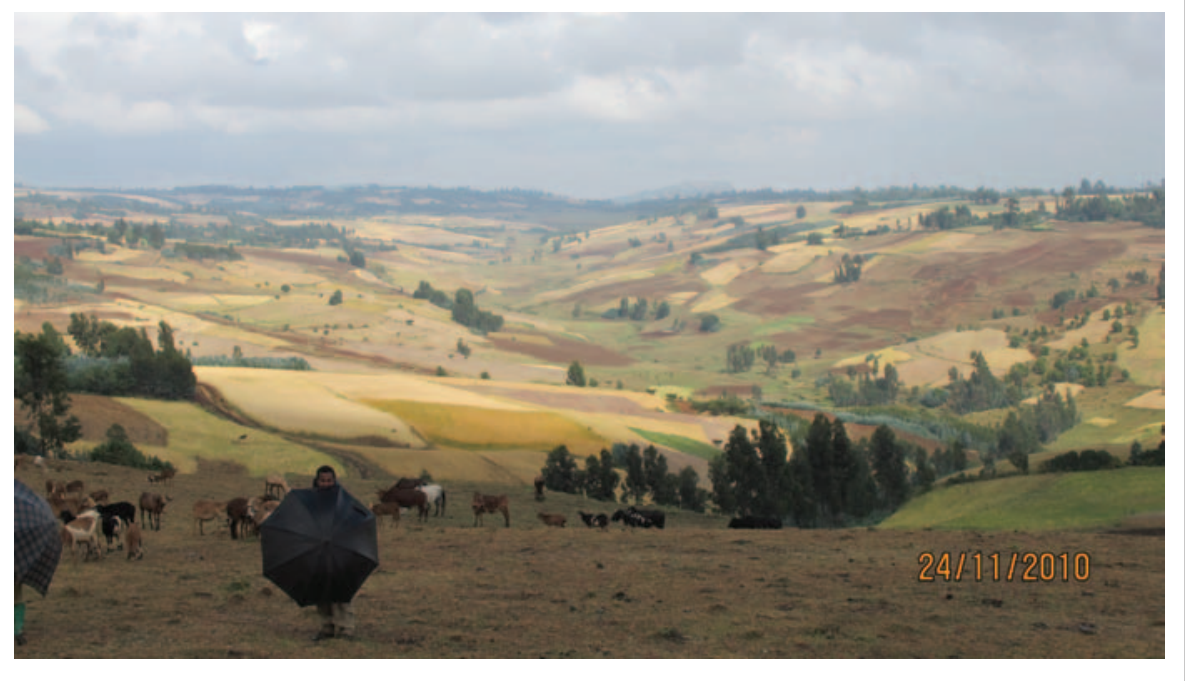

munity facilitation, team building, conflict resolution, and linkage creation across institutions. It was, therefore, difficult for them to smoothly exercise and attain a functional network. Moreover, they were engaged in so many competing activities that their ability to adequately follow and implement participatory approaches was minimized. Unlike on-farm trials where researchers can periodically check on progress, IPs require consistent and continuous engagement.

Leader roles and responsibilities require access to budgets and other resources, including direct transfer of funds from donors to local partners. This allows partners to become more responsive to new ideas and willing to innovate on their own rather than in centralized setups.

Knowledge Management. Production of various communication products responding to the needs of various clients is as important as generation of SLM technologies and practices. It demands identification of successful cases, documentation of insights, distillation of key lessons, continual facilitation of crossinstitutional learning, and sharing of both processes and outcomes with wider users.

Communication failures in both countries affected joint learning and exchange of SLM experiences and discouraged adaptive management. Limited communication caused some IP members (e.g., NGOs in Kapcherwa) to act in isolation. Nonparticipating farmers also had little information about neighboring farmers' activities, which became an obstacle to development of trust and cooperation. It is necessary to upgrade farmers' documentation skills. Well-designed knowledge management strategies are essential to promote SLM success stories. The team did not visualize a method to capture lessons and disseminate success stories to a broader scale. Nor did they allocate budgets for this.

Short-Term Benefits and Early Impact. Initial success takes a platform a long way. Seeing what a platform can do for an organization or individual is the best trigger for commitment and participation (Nederlof et al. 2011). However, it is important to mention that benefits from SLM are long-term public goods, rarely providing immediate incentives for investment and action. The benefits are also usually visible more at landscape scales than at individual household scales. Farmers who were convinced about long-term benefits of SLM didn't have incentives to operate beyond their vicinities and farms. One farmer, who is a member of the IP in Kaseko Watershed stated, "I have no time, no money, and no interest to think about scaling up. If it works in my farm, I will be very pleased. It is the responsibility of officers to take it elsewhere." Continued success and further expansion of IP activities is possible when farmers achieve early benefits, including fodder crops, fruits, high-yielding crop varieties, pest management options, veterinary services, and 
conflict resolution strategies. For instance, Dendi communities in Ethiopia jointly built a crossing point and rehabilitated a gully, which used to prohibit movement of livestock and people. Early impact was also a major incentive for local politicians (e.g., members of parliament) for winning elections, getting promotions, and winning political backing and recognition.

Policy Support and Action. The local IPs tended to be inward looking with little consideration of external drivers. Wider action and institutionalization of good practices can only happen when strong linkages are created with policy makers, who then use the evidence emerging from local IPs to introduce or modify policies. Policy support, through jointly approved bylaws, also helped manage free riders within the community, who knowingly or unknowingly complicated the engagement of communities. Local NGOs also follow directions of local governments. However, once the IPs were established, roles of the local governments were very much limited to occasional meetings and site visits, commonly to accompany external visitors. In some cases, the budget that was allocated for IPs was diverted to other activities.

Recognition and Rewards. Recognition by peers and authorities was a very important incentive in sustaining IPs, both for communities and local governments. For instance in the Ugandan site, work has attracted the attention of wider communities and policy makers and won a presidential award. Similarly, communities in Ethiopia planned to cover their upper hills with trees following reception of a local government award. The local administration and research institutes also proudly displayed their certificate to visitors and peers.

\section{CONCLUSION AND IMPLICATIONS}

Establishing and facilitating an IP that works for SLM is a complex engagement that may require creating strong linkages, facilitating actors, identifying champions, devolving both resources and responsibilities to national partners, managing knowledge proactively, creating regular mentoring and monitoring processes, and institutionalizing good practices.
The dynamic nature of SLM processes, conflict of interest among actors, power imbalances, and unclear roles and responsibilities made the effectiveness of IPs quite challenging. It is fundamental to employ innovation brokers, set up various communication tools, and create crossinstitutional linkages to cross-fertilize proven experiences. Innovation platforms that are set to achieve SLM objectives should be broad based and accommodate various actors. Despite the short duration, there are indications that IPs are good entry points to facilitate adoption of SLM and influence policy.

\section{ACKNOWLEDGEMENTS}

We would like to recognize Joy Tukahirwa (overall project coordinator, Uganda), Adugna Wakjira (deputy director general of the Ethiopian Institute of Agricultural Research [EIAR] and team member, Ethiopia), Kindu Mekonen (visiting scientist at the International Livestock Research Institute [ILRI], Ethiopia), William Wangore (project leader in Uganda and center director at the Ugandan National Agricultural Research Organization, Uganda), Bezaye Gorfu (project leader in Ethiopia), Yohannes Gojjam (livestock expert and team member, Ethiopia), and Atsede Solomn (crop researcher at EIAR, Ethiopia), for their valuable discussions, facilitating meetings, organizing field trips, and providing information. The honest feedback from communities was extremely educational. Alan Duncan (senior scientist, ILRI, Ethiopia) and Habtermariam Kassa (country representative of the Center for International Forestry Research, Ethiopia) provided valuable comments on the initial draft.

\section{REFERENCES}

Amede, T., H. Assefa, and A. Stroud (eds). 2004. Participatory Research in Action. Ethiopian Experiences. Addis Ababa, Ethiopia: Ethiopian Institute of Agricultural Research and African Highlands Initiative.

ASARECA (Association for Strengthening Agricultural Research in Eastern and Central Africa). 2012. Bye law development and implementation in Uganda. Entebbe, Uganda: Association for Strengthening Agricultural Research in Eastern and Central Africa. http:// www.asareca.org/content/bye-law-development-and-implementation-uganda.

Berry, L. 2003. Land degradation in Ethiopia: Its extent and impact. Rome, Italy: Food and Agriculture Organization and World Bank.
German, L., J. Mowo, T. Amede, and K. Masuki. 2012. Integrated Natural resources management in the highlands of Eastern Africa: From concept to practice. London: Earthscan.

Friis-Hansen, E., and D. Kisauzi. 2004. Uganda: Evolution of the extension-farmer relationship. In Extension Reform for Rural Development, Vol. 2, eds. W.M. Rivera and G. Alex. Privatization of extension systems: Case studies of international initiatives. Agriculture and Rural Development Discussion Paper 9. Washington, DC: World Bank.

Hall, A., G. Bocket, and S. Taylor. 2001. Why research partnerships really matter: Innovation theory, institutional arrangements and implications for developing new technology for the poor. World Development 29(5):783-797.

Edwards, J. 2012. Uganda Landslide 2012: Death toll rising in the Mount Elgon region, government confirms. Huffington Post, June 26, 2012. http://www.huffingtonpost.com/2012/06/26/ mount-elgon-landslide-2012-missinguganda_n_1626893.html.

International Food Policy Research Institute (IFPRI). 2012. Agricultural Extension and Advisory Services Worldwide. http://www.worldwideextension.org/africa/uganda/s-uganda.

Kilelu, C., L. Kerkx, and C. Leuwis. 2012. Unraveling Innovation Platforms: Insights from co-evolution of innovation in a smallholder dairy development program in Kenya. The Netherlands: Wageningen University. http://www.ifsa2012.dk/downloads/ WS2_3/Kilelu\%20et\%20al\%20_tjek\%20op\%20 p\%C3\%A5\%20denne.pdf.

Nederlof, S., M. Wongtschowski, and F. van der Lee (eds). 2011. Putting heads together. Agricultural Innovation Practices in practice. Bulletin 396, KIT Publishers.

Swaans, K., B. Cullen, A. van Rooyen, A. Adekunle, H. Ngwenya, Z. Lema, and S. Nederlof. 2013. Dealing with critical challenges in African IPs: Lessons for facilitation. Knowledge Management for Development Journal 9(3):116-135

Van Rooyen, A., and Sabine Homann. 2011. Innovation Platforms: A new approach for market development and technology uptake in Southern Africa. ICRISAT-Bulawayo. http://www.icrisat. org/locations/esa/esa-publications/Innovationplatform.pdf. 